\title{
A REVIEW: THERMO-MECHANICAL FATIGUE OF GREY CAST IRON FOR AUTOMOBILE APPLICATION AND EFFECTS OF ALLOYING ADDITIONS
}

Oyetunji Akinlabi, Olowodaran Babatope C., Alao Alice O, Barnabas Abel A., Omole Sylvester O., Babalola Saheed A Department of Metallurgical and Materials Engineering, Federal University of Technology Akure, Ondo State Nigeria

\begin{abstract}
The existing literature concerning the thermal fatigue of cast iron is reviewed. The thermal resistivity is clearly affected by the amount and morphology of graphite, alloying elements and matrix as well as by temperature gradients, which induced mechanical strains which generates stress fields in the material. The literature is consistent to some extent, but uncertainties still exist, for instance, about the effects of some alloying elements. A test devised to study material damage under these varying strain temperature histories is called the (thermomechanical fatigue) TMF test. In this type of test both the temperature and the mechanical strain imposed on the specimen are monitored. this review presents a concise study on the thermomechanical fatigue of grey cast iron and effects of alloying additions, heating and cooling modes and methods of determining the TMF, the test rig in carrying out the experimental process is mostly locally fabricated because there is no definite process in carrying out the TMF (thermomechanical fatigue).
\end{abstract}

Keywords: fatigue, thermal cycling, thermomechanical fatigue, Stress fields, alloying elements, crack growth.

\section{INTRODUCTION}

Most engineering components subjected to thermal cycles fails mostly as a result of crack nucleation and eventually crack growth induced by thermal fatigue crack mostly occur at the surface of components that are subjected to repaid heating and cooling, Andre etal., (2004). Azadi et al., (2015). Temperatures changes cause internal temperature gradients across components the leads to the development of stress fields in the component microstructure. Casati et al., (2017) Compressive stress develops in component at elevated temperature, Holmgren et al., (2001). there is constraint of the material surface to expand because of the cool interior, most times the material begin to yield in compression as the case of grey cast iron at elevated temperature and it begins to undergo plastic deformation and as it becomes plastically deformed the stress become relieved. Bagnoli et al., (2009). Chaboche et al., (2002). If the stress is relieved at elevated temperatures through plastic flow on cooling, residual tensile stress is generated within the material, Chaboche et al., (2002). Gong et al., (2007) repetition of these phenomenon leads to crack nucleation and crack propagation termed thermal fatigue failure mode, Degamo et al., (2003). The severity of this damage is dependent on properties of the material be it physical and mechanical which involves the microstructure and surface conditions, design and form of productions. Gaol et al., (2012)

\section{CAST IRON}

Cast iron is used absolutely for engineering purposes and its technology. like that of other alloys, it continues to be developed at highly refined levels. Loehe (2003) Cast iron is referred to as family of ferrous alloys that are composed of majorly iron, carbon silicon and some other alloying elements in small quantities that ensures the solidification of the final phase with a eutectic transformation. Mohanadzadeh (2009). Many casts iron contain up to 3\% silicon which promotes graphitization i.e. breaking up of (metastable) iron carbide into iron and graphite. Alp (2002). Cast irons are usually classified in range of $(2.11 \%$ to about $4.5 \%$ ) carbon content, according to their solidification morphology from the eutectic temperature. Cast iron can also be classified by their structure as ferritic, pearlitic, and combination of the two in as cast form. Adebayo (2002). Cast irons have relatively low melting temperatures and liquid-phase viscosities, do not form undesirable surface temperatures and undergo moderate shrinkage during solidification. Cast iron is synonymous in structure to pig iron produced by blast furnace, excepts that pig iron contains large amount of impurities. They are essentially 
remelted pig iron of which the composition has undergone some adjustments/refining during melting process, Adebayo (2002). Depending on chemical specifications, cast irons can be non-alloyed or alloyed. The range of alloyed irons is much wider, and they contain either higher amount of common components, such as silicon and manganese, or special additions, such as nickel, chromium, aluminum, molybdenum, tungsten, copper, vanadium, titanium, and more others. Henkel (2002). Cast irons popularity stems from the ability to cast complex shapes at relatively low cost and the wide range of properties that can be achieved by careful control over composition and cooling rate without radical changes in production methods. Milekhine (2003). Cast irons exist in four common classifications based on metallurgical characteristics. The classification categorizes cast irons in terms of solidification and microstructure. Gray cast iron are characterized by flaky graphite in either pearlitic or ferritic matrix ductile or nodular iron through the addition of magnesium, cerium or in a process known as "nodularisation" produces ductile iron with spheroidal or nodular graphite similarly in either perlitic or ferritic matrix. Henkel (2002). Most common of cast iron is the grey cast iron which under consideration in this review is characterized by its graphitic microstructure, which causes fractures of the material to have a grey appearance, Donald et al., (2011). Grey cast iron contained large portion of its carbon in the form of graphite flakes. Although they are often defined as steel containing graphite, its properties are far different from those of steels. Grey cast iron has less tensile strength and shock resistance than steel, but its compressive streng this comparable to low- and mediumcarbon steel Alp (2002) The graphite flakes, which are rosettes in three dimensions, have a low density and hence compensate for the freezing contraction, thus giving good castings void of porosity Chandraprakash (2013).

\section{THERMOMECHANICAL FATIGUE}

A series of industrial products like internal-combustion engines, turbines, nuclear reactors, etc. are subject to thermomechanical loading cycles. Holmegren et al., (2011) The actual design process is constrained by a series of specifications such as energy consumption, lifetime, manufacturing processes, materials, production rates. Niklas (1994). In thermomechanical fatigue external constraining forces are effective in contrast to thermal fatigue, where internal constraints are

'relevant. Roheere et al., (2013) Structural components and mechanical equipment are often subjected to cyclic straining while operating at cycling temperatures. Loehe (2003) In some cases, the temperature may be relatively constant, but in other cases the cyclic straining may be combined with thermal cycling. Pierce et al., (2018) The problem is even more complicated, if time relationship between temperature and strain must be taken into account. Hosdez et al., (2019).TMF-testing is characterized by a cyclic temperature load with the presence of mechanical loadings. When performing TMF testing, strain controlled load scenarios is used and there are three different strains that needs to be considered as seen in equation below.

$$
\varepsilon_{\text {tot }}=\varepsilon_{m e}+\varepsilon_{t h}
$$

Niklas (1994)

These are the total strain, which is measured by an extensometer. The thermal strain that is a result from the thermal expansion and the mechanical strain defined as stress divided by the material stiffness.

\section{THERMAL FATIGUE}

Thermal fatigue is the gradual deterioration and eventual cracking of a material by alternate heating and cooling during which free thermal expansion is partially or completely constrained. Thermal fatigue is usually considered as a low cycle fatigue phenomenon, which is commonly defined as the regime where plastic strain in each cycle exceeds the elastic strain. Niklas (1994).

Several factors are controlling the initiation and propagation of thermal fatigue cracks. Mohebbi et al., (2010). Some of the most important ones are the cycling parameters which are temperature range, maximum temperature, heating and cooling modes, rates, and holding times, some mechanical properties of the material, hardness, ductility, strength, other properties such as thermal conductivity, coefficient of thermal expansion the surface morphology, Richard (2019) the microstructural characteristics which includes grain size, carbides, the form of component design process and the environment in which the material is been put to use.

\section{Heating and cooling modes}

In thermal fatigue study several methods for heating and cooling have been adopted, but there is no much information for the choice of specific systems available. Sehioghu (1992) In recent study methods for cyclic heating of test specimen include gas burner rigs, electrical resistance, fluidized beds, high frequency induction and radiation heating. Knut et al., () Water bath, water spray, a cold fluidized bed and air have been mostly used for cooling. Zhang et al., (2017) The criteria for choosing a certain heating or cooling technique could be the following, temperature range and maximum temperature heating and cooling rates specimen geometry, testing material, and thermal load among others. Barnes et al (1997). 


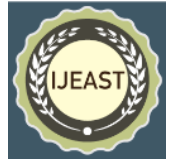

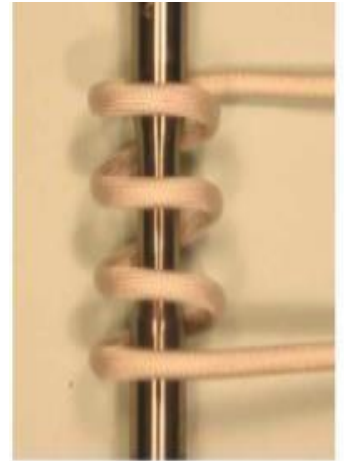

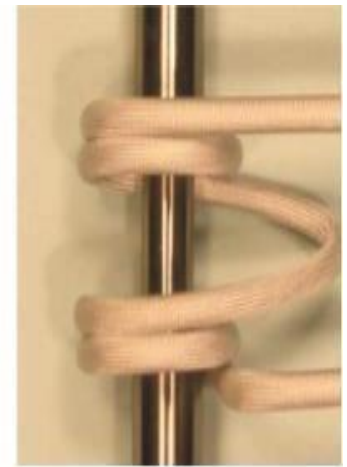

Fig.1: Setup for induction coil heating mode. Huter et al., (2016)

\section{METHODS OF DETERMINING THE TMF}

In the modification of mechanical properties of grey cast iron in terms of the thermomechanical properties Casati et al., (2017) studied microstructural evolution and thermal fatigue resistance of grey cast iron looked into thermal fatigue in grey cast iron has been investigated by means of a numerical and an experimental approach.

Temperature gradients were generated within the material by means of a testing rig specifically designed for the experiments. Casati et al., (2017) also record that temperature gradients were responsible for the formation of severe stress fields that led to the failure of the specimens after a fairly low number of cycles. Crack growth was monitored during the tests, and the microstructure and hardness of samples were analyzed after failure and compared with those of untested alloy.

The samples are heated by an induction coil, then cooled in air, and finally dip in a water tank. The thermal cycles induced on specimens are continuously repeated by wheel rotation

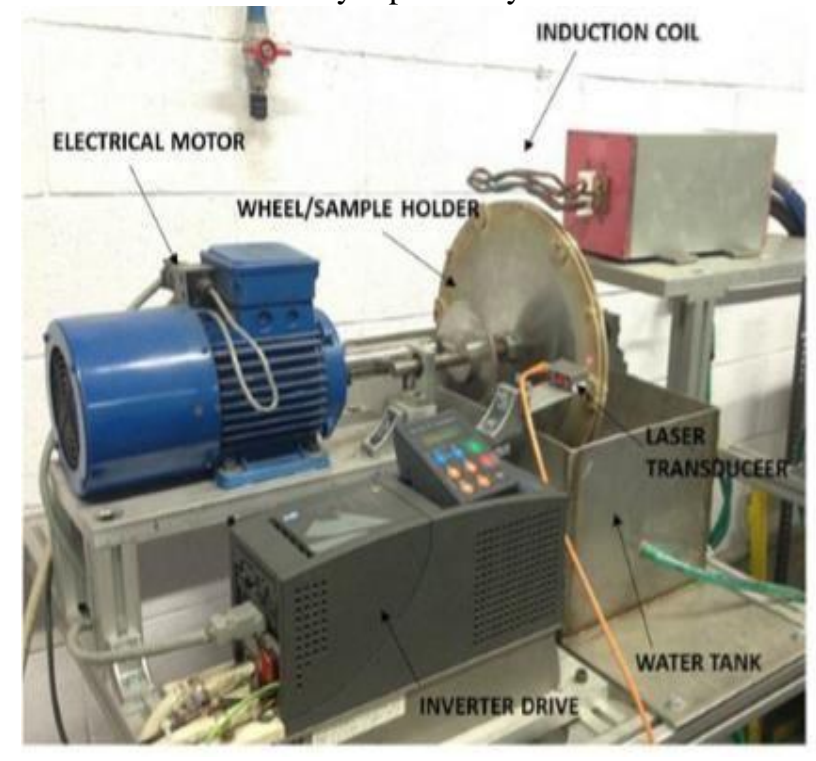

Fig. II: A locally fabricatedtest rig, for thermomechanical fatigue test. Casati et al., (2017)

The number of cycles was counted by using a laser transducer. Tests were run until final rupture of the specimens occurred or by setting a runout limit of 2000 cycles. $\mathrm{K}$ type thermocouples were welded on the cast iron samples to monitor the temperature during thermal cycles.

The repeated thermal cycles at peak temperatures of 600 , 700 , and $800^{\circ} \mathrm{C}$ led to important microstructural alterations of cast iron and to a drop in material hardness. The pearlite lamellae lost their original shape and became more fragmented. Niklas (1994) Oxygen_rich regions surrounding the graphite flakes were produced by micro galvanic corrosion mechanism. Repeated thermal cycling between 700 or $800^{\circ} \mathrm{C}$ and room temperature induced important alterations of the cast iron microstructure, also leading to a drop in material hardness.

Thermal fatigue tests led to a modification of the pearlite lamellae, which lose their original shape and became more fragmented. Oxygen_rich regions surrounding the graphite flakes were likely produced by local galvanic corrosion that occurred between the cathodic graphite flakes and the anodic ferritic matrix. Those areas are characterized by reduced hardness and are suggested to play a significant role in reducing the ThF resistance of the material. Bernoli et al (2009) Also there is a similar research carried out by Charkaluk et al., (2002) studied a computational approach to thermomechanical fatigue complete lifetime estimation approach has been derived for structures undergoing thermomechanical fatigue and applied to the design of cast iron exhaust manifolds. The structural approach integrates a simple elastoviscoplastic description of the high temperature behavior of the material. This material law allows sufficient precision without major CPU time increase, implying that this approach can be included in a classical development schedule of such parts. The results of these computations, associated with a reasonable simple an isothermal LCF criterion, show good agreement between predicted and observed critical zones for two versions of a given manifold. This approach is not limited to exhaust manifolds or cast iron: further applications could concern steel or aluminum alloys and other parts in the automotive industry or elsewhere.

In the study of thermomechanical processing of advanced high strength steels, progress in Materials Science by England et al., (2018) Thermomechanical processing (TMP), a combination of deformation and heat treatment, is established and strategic method for improving the mechanical properties of AHSSs (advanced high strength steels). through control of their microstructure. TMP is 


\section{International Journal of Engineering Applied Sciences and Technology, 2020 Vol. 5, Issue 4, ISSN No. 2455-2143, Pages 17-25 \\ Published Online August 2020 in IJEAST (http://www.ijeast.com)}

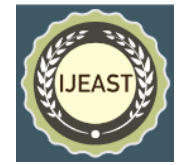

among the most important industrial technologies for producing high quality AHSSs with the required mechanical properties. It improves the microstructural features in order to realize the AHSS products fitting the requirements imposed by modern automotive technology.

TMP is a metallurgical process that integrates work hardening and heat treatment into a single process Degamo et al., (2003) It is principally applied to the processing of metallic alloys, but it has also found applications in the manufacturing of ceramics, polymers and many of their combinations, Verlinden et al., (2007). The TMP method was first introduced into commercial production of $\mathrm{C}-\mathrm{Mn}$ steel plates in the 1950 s by means of controlled rolling Mellouli et al., (2014) and increasingly it has become an important technique in the process design of controlled rolling, cooling and direct quenching of many steel products, such as plates, sheets, strips, beams, bars, wires, pipes and rails.

The key feature of TMP is its sophisticated combination of well-defined deformation operations and well defined heat treatment. Absi et al., (2004) And concludes that The relationship between processing, microstructure, mechanical properties and workability should also be considered in TMP schedule designs in order to avoid defects, such as cracking, in the production of AHSS.

Also thermal fatigue characteristics of gray cast iron with non-smooth surface treated by laser alloying of $\mathrm{Cr}$ Powder was investigated by Zhao et al., (2018). Thermal fatigue tests were carried out by a selfrestrain thermal fatigue testing machine. The samples were heated by a high temperature electric resistance furnace, and cooled by running water. This machine could record thermal cycle times automatically. The furnace temperature was controlled, and the sample temperature was monitored by a thermocouple attached to the sample. the center of its length. A complete thermal cycle includes heating to $500 \pm 5^{\circ} \mathrm{C}$ in $70 \mathrm{~s}$, and then cooling to $25 \pm 5^{\circ} \mathrm{C}$ in $3 \mathrm{~s}$. The samples were free from any externally applied load, and were taken out to observe the cracks every 200cycles. Depth and width of the unit were evaluated using an optical microscope. Microstructure was characterized. Stereomicroscope was used to study the initiation and propagation of thermal cracks. Zhao et al., (2018)

\section{a. Influence of cycling parameter on thermal fatigue}

Since thermal fatigue is caused by rapid changes of temperature it is obvious that all variables that determine the time-temperature-cycle have a significant influence On the fatigue process, Holmegren et al., (2001) Temperature range, maximum temperature, minimum temperature, heating and cooling rates and hold times are considered to be the most important parameters in thermal cycles of materials. Niklas (1994)

\section{b. Temperature difference and temperature change}

Temperature range can influence the thermal fatigue behavior of materials. In his test to evaluate the thermal fatigue resistance of cast irons Rhoerig (1974) for example, raised both maximum temperature of $420{ }^{\circ} \mathrm{C}$ and minimum temperature of $20^{\circ} \mathrm{c}$ by $200{ }^{\circ} \mathrm{c}$, in order to shift the temperature, range to higher temperatures without changing the temperature difference. Before the temperatures were raised, the material was in a condition where stress relaxation was not possible.

With the shift of the cycle to higher temperatures the material was most of the time in a temperature range, in which stress relaxation was possible and therefore in this case the thermal fatigue resistance was increased. In other cases, shifting of the temperatures to a range where stress relaxation was possible, did not result in a better thermal fatigue resistance Verlinden et al., (2007). If, for instance, temperatures are reached where increasing oxidation and creep have a significant influence, the thermal fatigue resistance might be diminished.

\section{c. Heating and cooling rates}

Heating and cooling rates are also very essential parameters in thermal fatigue. Klobcar et al., (2008) Different cooling rates can be achieved with different cooling media. To achieve high rate of cooling water is to be provided for quenching, knut et al., (1993) for a lower rate of cooling forced air or pressurized air is to be adopted for cooling. Heating rates can be monitored by either varying the power input of the source of heat or, if fluidized beds are used for heating, with different bed temperatures. Knut et al., (1993) High rates of cooling and heating as compared to low rates generally lead to steep temperature gradients which cause higher thermal stress and result in shorter fatigue lives, when using high rates of heating and cooling, the thermal fatigue resistance of cast irons was mainly dependent on the carbon content, Birol (2010) whereas in temperature cycles with lower heating and cooling rates the thermal fatigue resistance was also dependent on the strength of the cast iron. Birol (2011) The higher the heating and cooling rates, the more important was the carbon content of the certain material. Lee et al., (2017) A high carbon content results in a high thermal conductivity and therefore in a reduction of temperature differences between surface and the interior. 


\section{International Journal of Engineering Applied Sciences and Technology, 2020 \\ Vol. 5, Issue 4, ISSN No. 2455-2143, Pages 17-25 \\ Published Online August 2020 in IJEAST (http://www.ijeast.com)}

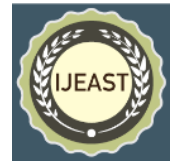

\section{d. Influence of alloying elements}

To understand the influence of alloying elements on thermal properties of metals Huter et al.,

(2016) studied thermo-mechanical fatigue influence of copper and silicon on hypo-eutectic $\mathrm{Al}-\mathrm{SiCu}$ and $\mathrm{Al}-\mathrm{Si}$ -

$\mathrm{Mg}$ cast alloys used in cylinder heads.in this paper, different hypo-eutectic AL-Si cast alloys with varying silicon, copper and iron contents were tested under thermomechanical fatigue (TMF) conditions to achieve a unified approach to damaging and fatigue endurance behavior. The cylinder heads from which the specimens were taken were serially produced with T79 heat treatment. This includes homogenization, quenching and ageing. The alloy used by these investigations are commonly used for automotive cylinder heads. Under operational conditions, a complex interaction of mechanical and thermal cyclic loadings is inherent. Verlinden et al., (2007) Hence, the main purpose here is to distinguish between the influences of the alloying elements of hypo-eutectic Al-Si cast alloys and propose its effects to mechanical and environmental damages.

Copper increases thermal endurance but reduces corrosion resistivity. Magnesium, on the other hand, also acts as a precipitation hardening element and has good corrosion resistance but lacks in high temperature regimes. Sinharoy et al., (2004) In addition, heat treatment also influences fatigue behavior. For automotive application. The silicon and copper contents of hypo-eutectic Al-Si alloys play a major role for the TMF endurance behavior by particle interactions and not defect based damaging Degamo et al., (2003).
It is found that molybdenum enhances TMF-life while no such effect is seen for niobium. Niobium on the other hand has a larger effect on static strength than molybdenum and also on the cyclic stress in the thermo-mechanical fatigue experiments according to Skoglund et al., (2008).

The increased TMF-life is attributed to either an increase of the total crack length or to an increased crack propagation resistance of the matrix when the solidification time goes from medium to short. Xin Tong et al., (2008) Since the stress levels that drives the crack propagation are very similar for the medium and short solidification times. On the other hand, the TMF-life increases more when going from medium to short solidification time compared to from long to medium time. Zhu (2004).

\section{CRACK GROWTH}

The characteristics of crack initiation and propagation depend on the observation positions of specimens, because the specimens are not homogeneous, not heated and not cooled uniformly.

Goo et al., (2010) Here spots were examined on the surface of each specimen and measured total crack length on each spot. Fig below shows the development of thermal cracks after 780 thermal cycles in the specimen made from a conventional disk in service use also shows the total crack length on the spots. It is found the candidate materials are more resistant to thermal shock loading. In the case of conventional material, the initiation life of thermal fatigue is shorter than the material observed. Goo et al., (2018).

Fig below shows the crack propagation rates.

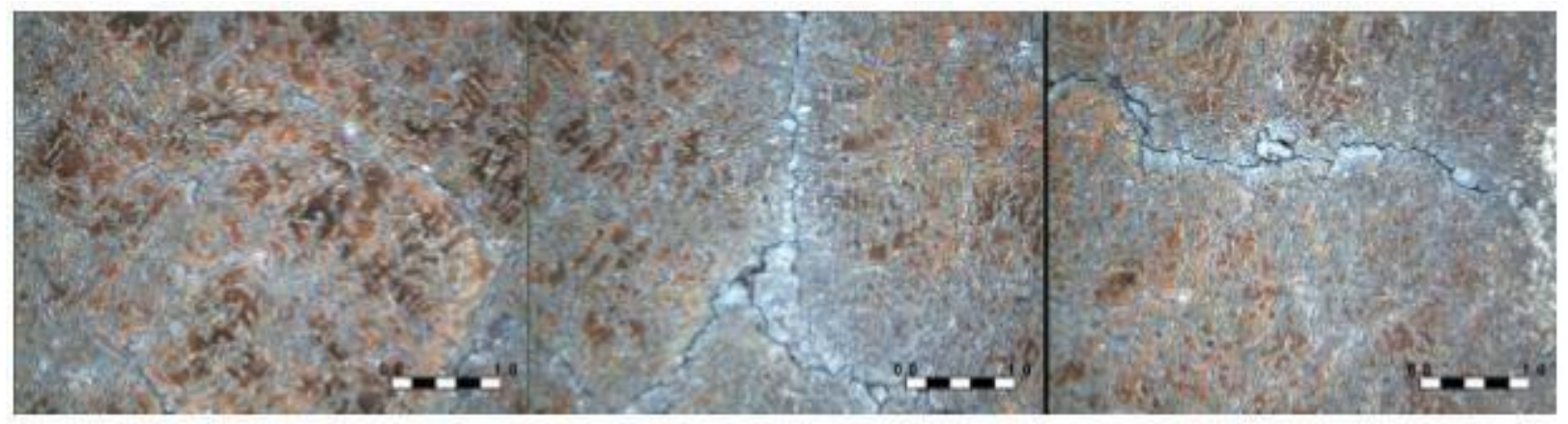

(a) Observation spot 1

(b) Observation pot 2

(c) Observation spot 3

Cracks in material (grey cast iron with nickel addition) after 780 thermal cycles. Goo et al., (2018) 


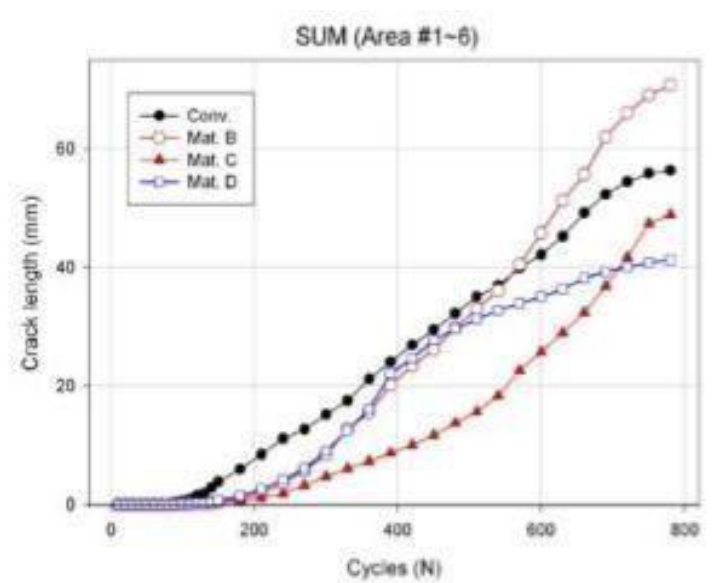

Total crack length vs thermal cycles. Goo et al., (2018) Crack propagation rate versus thermal cycles Goo et al., (2018)

Thermal fatigue tests for three candidate cast iron and a specimen made from a disc in service use. The temperature range for the thermal fatigue was 25 600. Goo et al., (2018)

\section{CONCLUSION}

The overall aim of this review is to examine thermomechanical fatigue of grey cast iron for automobile application and effects of alloying additions. under different temperature working conditions, repeated thermal cycling between 300 to $800^{\circ} \mathrm{C}$ and cooling to room temperature lead to important alterations of cast iron microstructure, also leading to a reduction in material hardness. Thermal fatigue tests led to a modification of the pearlite lamellae, which lose their original shape and became more fragmented. Verlindin et al., (2007) Cracking as a result of thermal fatigue where no additional loading by external stresses is involved mostly occurs at the surface of components that are subjected to rapid heating or cooling. The constraints in thermal fatigue are called internal constraints, because the sudden temperature changes cause internal temperature gradients across the component. Klobcar et al., (2008) These in turn produce stress gradients, which originate simply because heat is unable to flow fast enough in response to the external changes. As a result, very often local yielding on the surface occurs, which very often leads to the initiation of a crack after a certain amount of cycles.

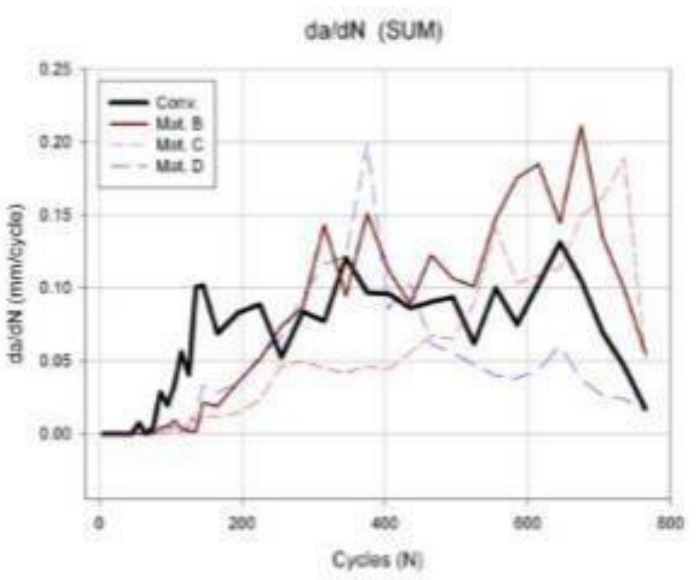

VIII.

\section{REFERENCE}

[1] Andrei Constantinescu, Eric Charkaluk, Guy Lederer, Laetitia Verger (2004). A Computational Approach

Thermomechanical Fatigue.pp. 12

[2] Azadi, M G. H. Farrahi, G. Winter, P. Huter, W. Eichlseder, Damage prediction for uncoated and coated aluminum alloys under thermal and mechanical fatigue loadings based on a modified plastic strain energy approach, Materials and Design 66, Part B (0) (2015) lightweight Materials and Structural Solutions for Transport Applications. Pp.587 - 595

[3] Bagnoli F, Dolce F, Bernabei M. (2009). Thermal Fatigue Cracks of Gray Iron Brake

Fire fighting VehiclesDiscs. Eng Fail Anal 2009;16:pp. 152163

[4] Casati, R, Faccin R, Vedani M. (2017): Microstructural Evolution and Thermal Fatigue Resistance of Grey Cast Iron. Fatigue Fracture Engineering Materials Structure Pp. 1-13

[5] Charkaluk E, Bignonnet A, Constantinescu A, Dang Van K. (2002) Fatigue design of structures under thermomechanical loading. Fatigue Fracture Engineering Materials Structure;pp.25.

[6] Chaboche JL, Gallerneau F. (2002). An overview of the damage approach of durability modelling at elevated temperature. Fatigue Fract Eng Mater Struct 2002;24(6):405-18 pp7

[7] Charkaluk E, Constantinescu A. (2002). An energetic approach in thermomechanical 


\section{International Journal of Engineering Applied Sciences and Technology, 2020 \\ Vol. 5, Issue 4, ISSN No. 2455-2143, Pages 17-25 \\ Published Online August 2020 in IJEAST (http://www.ijeast.com)}

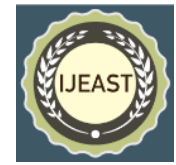

fatigue For silicon molybdenum cast iron. Mater High Temp 2000;17(3):373-p.80.

[8] DeGarmo EP, Black JT, Kohser RA. Materials and Process in Manufacturing (9th edition). Wiley; 2003. Pp.7-9.

[9] Gao Lul wen., yan Wang, b,Jing pei Xie (2012).The Thermal Fatigue Performance for Cast Iron Brake Drum of Large Trucks,a,Wen,c 1Material Science and Technology Institution, Henan University of Science and Technology, Luoyang 471003, China. Pp.13-15

[10] Gong P, Palmiere EJ, Rainforth WM. Thermomechanical Processing Route to Achieve Ultrafine Grains in Low Carbon Micro Alloyed Steels. Acta Mater 2016; 119: Pp43-54.

[11] Holmgren., D and I.L. Svensson Thermal Conductivity-Structure Relationships In Grey Cast Iron Department of Mechanical Engineering and Industrial Organisation, Jo"nko"ping University, S-551 11 Jo"nko" ping, Sweden. Pp 11-17.

[12] Regheere $\mathrm{G}$, Collignon M, Cristol AL, Desplanques Y, Dufrenoy P,Balloy D.(2013).,

Thermocracks, A Specific Testing Machine for Evaluation of the Thermal Fatigue Resistance of Materials. Proc Eng. 2013; 66:Pp250 263.

[13] Mohebbi H, Jesson DA, Mulheron MJ, Smith PA. The Fracture and Fatigue Properties of Cast Irons used for Trunk Mains in The Water Industry. J Mater Sci Eng A. 2010; 527:5915_5923. Pp 8-12.

[14] Niklas Colin., Thermomechanical Fatigue of Cast Iron for Rngine Application Master of

Science Thesis MMK 2014:14 MKN104 KTH Industrial Engineering and Management Machine Design SE-100 44 STOCKHOLM pp34.

[15] Loehe, D T. Beck, K. Lang, Important aspects of cyclic deformation, damage and lifetime

behaviour in thermomechanical fatigue of engineering alloys, in: Fifth international conference on low cycle fatigue. DVM, Berlin, Germany, 2003, pp. 161-171

[16] Pierce, D., Haynes, A., Hughes, J., Graves, R., Maziasz, P., Muralidharan, G., Shyam, A.,

Wang, High Temperature Materials for Heavy Duty Diesel Engines: Historical and Future
Trends, Progress in Materials Science (2018) pp 32.

[17] Knut Barts., Hannu Hanninea., Marku Nieminei, Thermal fatigue a literature review. Helsinki University of Technology, Faculty of mechanical engineering, laboratory of engineering materials. Pp 5-23.

[18] Huter, P., Oberfrank, S., Grün, F., Stauder, B., (2016). Thermo-mechanical Fatigue Influence of Copper and Silicon on hypoeutectic $\mathrm{Al}-\mathrm{Si}-\mathrm{Cu}$ and $\mathrm{Al}-\mathrm{Si}-\mathrm{Mg}$ cast alloys used In cylinder heads, International Journal of Fatigue. Pp 36.

[19] Hosdez, J., Limodin, N., Najjar, D., Witz, J-F., Charkaluk, E., Osmond, P., Forré, A., Szmytka, F., (2019). Fatigue Crack Growth in Compacted and Spheroidal Graphite Cast Irons, International Journal of Fatigue. Pp 1125.

[20] Richard W. Neu (2019). Crack paths in singlecrystal Ni-base Superalloys Under Isothermal and Thermomechanical Fatigue, International Journal of Fatigue. Pp 7-14.

[21] Rukadikar M C, Reddy G P. Influence of Chemical Composition and Microstructure On Thermal Conductivity of Alloyed Pearlitic Flake Graphite Cast Irons. J. Mater. Sci., 1986, 21(12): PP.3-33.

[22] Sinharoy S, Narasimhan SL. (2004), Oxidation Behavior of Two Nickel-Base Superalloys

Used as Elevated Temperature Valves in Spark Ignited Engines and Diesel Exhaust

Recirculation (EGR) applications, The Minerals, Metals \& Materials Society. Pp.7-25.

[23] Verdu, C J Adrien, and JY Buffiere. (2008) Three-dimensional Shape of the Early Stages

of Fatigue Cracks Nucleated in Nodular Cast Iron. Materials Science 900 and Engineering: A, 483:402-405, 2008

[24] Verlinden B, Driver J, Samajdar I, Doherty RD. (2007) Thermo-Mechanical Processing Of Metallic Materials. Elsevier. pp.4-26.

[25] H. Sehitoglu, (1992) Thermo-mechanical Fatigue Life Prediction Methods. Advances in Fatigue Lifetime Predictive Techniques, ASTM International, Pp.23-28.

[26] M.X. Zhang, J.C. Pang, Y. Qiu, S.X. Li, M. Wang, Z.F. Zhang, (2017) Thermomechanical fatigue property and life prediction 


\section{International Journal of Engineering Applied Sciences and Technology, 2020 \\ Vol. 5, Issue 4, ISSN No. 2455-2143, Pages 17-25 \\ Published Online August 2020 in IJEAST (http://www.ijeast.com)}

of vermicular graphite iron, Mater. Sci. Eng. Pp 21.

[27] B.C. Goo, C.H. Lim, Development of brake disc materials with long thermal fatigue life, 9th International ASTM/ESIS Symposium on Fatigue and Fracture Mechanics (2009).

[28] B.C. Goo, C. H. Lim Thermal Fatigue Evaluation of Cast Iron Discs for Railway Vehicles. (2010) Procedia Engineering Pp.680-684

[29] Barnes DJ, Stott FH, Wood GC. The Frictional Behavior of Iron and IronChromium

Alloys at Elevated Temperatures. International journal of Wear 1977; 45:Pp199-209

[30] D. Mellouli, N. Haddar, A. Köster, H. F. Ayedi, Hardness effect on thermal fatigue damage of hot-working tool steel, Engineering Failure Analysis, 45 (2014) Pp.85-95.

[31] J. Absi, J.C. Glandus, Improved methods for severe thermal shocks testing of ceramics by water quenching, Journal of European Ceramic society, 24 (2004) Pp.2835-2838.

[32] D. Klobčar, J. Tušek, Thermal stresses in aluminium alloy die casting dies. Computational Materials Science, 43 (2008). Pp.47-54.

[33] D. Klobčar, J. Tušek, B. Taljat, Thermal fatigue of materials for die-casting tooling.

Materials Science and Engineering, A 472 (2008). Pp.198-207.

[34] Y. Birol, Effect of post-oxidation treatment on thermal fatigue behaviour of plasma nitrided

hot work tool steel at elevated temperatures, Surface and Coatings Technology, 205 (2010) Pp.597-602.

[35] Y. Birol, Response to thermal cycling of duplex-coated hot work tool steels at elevated temperatures, Materials Science and Engineering, A 528 (2011) 8402-8409.

[36] [36] Y. Zhu, D. Schwam, J.F. Wallace, S. Birceanu, Evaluation of soldering, washout and thermal fatigue resistance of advanced metal materials for aluminum die-casting dies. (2004) Materials Science and Engineering, A 379. Pp.20-31.

[37] S. LeRoux, F. Medjedoub, G. Dour, F. RézaïAria, Role of heat-flux density and mechanical loading on the microscopic heat-checking of high temperature tool steels under thermal fatigue experiments. (2013) International Journal of Fatigue.pp15-25.

[38] S. Lee, D.H. Kim, J.H. Ryu, K. Shin, Correlation of Microstructure and Thermal Fatigue Property of Three Work Rolls. (1997) Metallurgical and Materials Transaction,

[39] C.K. Kim, J.I. Park, J.H. Ryu, S. Lee, Correlation of Microstructure and Thermal Fatigue Property of Centrifugal Cast HighSpeed Steel Rolls. (2004) Metallurgical and Materials Transaction, pp. 481-492.

[40] B., England, R., Daniel, C., (2018). High Temperature Materials for Heavy Duty Diesel

Engines: Historical and Future Trends, Progress in Materials Science. Pp.23-39

[41] Zhao, J., Jiang, Z., Thermomechanical processing of advanced high strength steels. (2018) Progress in Materials Science. Pp. 34.

[42] Xin Tong., Hong Zhou., Lu-quan Ren., ZhiZhang., Ren-dong Cui., Wei Zhang., Thermal

fatigue characteristics of gray cast iron with noon smooth surface treated by laser alloying of Cr powder. Pp.2528-2534.

[43] Skoglund,Peter. Nulifer.,Ipek Jessica Elfsberg., Lucian Diaconu.ThermoMechanical Fatigue of Grey Cast Iron for Cylinder Heads Effect of Niobium, Molybdenum and Solidification Time (2018). pp 3-8.

[44] Roehrig k., (1978) Thermal Fatigue of gray and ductile irons. AFS Trans 86: pp.75-88

[45] Adebayo, A. O. (2019): Structural Characterization and Mechanical Properties of Rotary Melting Furnace Processed Aluminium Alloyed Ductile Irons: Journal of Taibah University for Science: Vol 13, Pp 116.

[46] Alp, T., Yilmaz F. and Wazzan A. A. (2002): Microstructural Characteristic-Property Relationships in Cast Iron. The $6^{\text {th }}$ Saudi Engineering conference, Vol. 5, Pp 281-285 [47] Chandraprakash R., (2013): Effect of Inoculation $\mathrm{On}$ the Microstructure and Mechanical

Properties of Grey Cast Iron, Ganpat University, North Gujarat. Pp78-95. 
[47] Donald, R.A., Pradeep, P. F., Wendelin, J. W. (2011): The Science and Engineering of Material", 6th ed. Cencage Learning. Stamford USA. Pp. 523-529.

[48] Henkel, and Pense. (2002): Structure and Properties, of Engineering Materials, McGraw Hill Higher Education 234-432.

[48] Milekhine, V. (2003): High Performance Cast Irons, Norwegian University of Science and Technology. 321-401.

[49] Mohamadzadeh, H., Saghafian H. and Kheirandish, S. H. (2009): Sliding Wear Behavior of a Grey Cast Iron Surface Remelted by TIG, Journal of Materials Science and Technology, Vol. 25 No. 5, Pp. 622-628. 